\title{
Implementing electronic health records in hospitals: a systematic literature review
}

Albert Boonstra ${ }^{1 *}$, Arie Versluis ${ }^{2}$ and Janita F J Vos ${ }^{1}$

\begin{abstract}
Background: The literature on implementing Electronic Health Records (EHR) in hospitals is very diverse. The objective of this study is to create an overview of the existing literature on EHR implementation in hospitals and to identify generally applicable findings and lessons for implementers.

Methods: A systematic literature review of empirical research on EHR implementation was conducted. Databases used included Web of Knowledge, EBSCO, and Cochrane Library. Relevant references in the selected articles were also analyzed. Search terms included Electronic Health Record (and synonyms), implementation, and hospital (and synonyms). Articles had to meet the following requirements: (1) written in English, (2) full text available online, (3) based on primary empirical data, (4) focused on hospital-wide EHR implementation, and (5) satisfying established quality criteria.

Results: Of the 364 initially identified articles, this study analyzes the 21 articles that met the requirements. From these articles, 19 interventions were identified that are generally applicable and these were placed in a framework consisting of the following three interacting dimensions: (1) EHR context, (2) EHR content, and (3) EHR implementation process.

Conclusions: Although EHR systems are anticipated as having positive effects on the performance of hospitals, their implementation is a complex undertaking. This systematic review reveals reasons for this complexity and presents a framework of 19 interventions that can help overcome typical problems in EHR implementation. This framework can function as a reference for implementers in developing effective EHR implementation strategies for hospitals.
\end{abstract}

\section{Background}

In recent years, Electronic Health Records (EHRs) have been implemented by an ever increasing number of hospitals around the world. There have, for example, been initiatives, often driven by government regulations or financial stimulations, in the USA [1], the United Kingdom [2] and Denmark [3]. EHR implementation initiatives tend to be driven by the promise of enhanced integration and availability of patient data [4], by the need to improve efficiency and cost-effectiveness [5], by a changing doctor-patient relationship toward one where care is shared by a team of health care professionals [5], and/or by the need to deal with a more complex and rapidly changing environment [6].

\footnotetext{
* Correspondence: albert.boonstra@rug.nl

${ }^{1}$ Faculty of Economics and Business, University of Groningen, Groningen, The Netherlands

Full list of author information is available at the end of the article
}

EHR systems have various forms, and the term can relate to a broad range of electronic information systems used in health care. EHR systems can be used in individual organizations, as interoperating systems in affiliated health care units, on a regional level, or nationwide [1,2]. Health care units that use EHRs include hospitals, pharmacies, general practitioner surgeries, and other health care providers [7].

The implementation of hospital-wide EHR systems is a complex matter involving a range of organizational and technical factors including human skills, organizational structure, culture, technical infrastructure, financial resources, and coordination [8,9]. As Grimson et al. [5] argue, implementing information systems (IS) in hospitals is more challenging than elsewhere because of the complexity of medical data, data entry problems, security and confidentiality concerns, and a general lack of awareness of the benefits of Information Technology 
(IT). Boonstra and Govers [10] provide three reasons why hospitals differ from many other industries, and these differences might also affect EHR implementations. The first reason is that hospitals have multiple objectives, such as curing and caring for patients, and educating new physicians and nurses. Second, hospitals have complicated and highly varied structures and processes. Third, hospitals have a varied workforce including medical professionals who possess high levels of expertise, power, and autonomy. These distinct characteristics justify a study that focuses on the identification and analysis of the findings of previous studies on EHR implementation in hospitals.

\section{Study aim, theoretical framework, and terminology}

In dealing with the complexity of EHR implementation in hospitals, it is helpful to know which factors are seen as important in the literature and to capture the existing knowledge on EHR implementation in hospitals. As such, the objective of this research is to identify, categorize, and analyze the existing findings in the literature on EHR implementation processes in hospitals. This could contribute to greater insight into the underlying patterns and complex relationships involved in EHR implementation and could identify ways to tackle EHR implementation problems. In other words, this study focusses on the identification of factors that determine the progress of EHR implementation in hospitals. The motives behind implementing EHRs in hospitals and the effects on performance of implemented EHR systems are beyond the scope of this paper.

To our knowledge, there have been no systematic reviews of the literature concerning EHR implementation in hospitals and this article therefore fills that gap. Two interesting related review studies on EHR implementation are Keshavjee et al. [11] and McGinn et al. [12]. The study of Keshavjee et al. [11] develops a literature based integrative framework for EHR implementation. McGinn et al. [12] adopt an exclusive user perspective on EHR and their study is limited to Canada and countries with comparable socio-economic levels. Both studies are not explicitly focused on hospitals and include other contexts such as small clinics and national or regional EHR initiatives.

This systematic review is explicitly focused on hospitalwide, single hospital EHR implementations and identifies empirical studies (that include collected primary data) that reflect this situation. The categorization of the findings from the selected articles draws on Pettigrew's framework for understanding strategic change [13]. This model has been widely applied in case study research into organizational contexts [14], as well as in studies on the implementation of health care innovations
[15]. It generates insights by analyzing three interactive dimensions - context, content, and process - that together shape organizational change. Pettigrew's framework [13] is seen as applicable because implementing an EHR artefact is an organization-wide effort. This framework was specifically selected for its focus on organizational change, its ease of understanding, and its relatively general dimensions allowing a broad range of findings to be included. The framework structures and focusses the analysis of the findings from the selected articles.

An organization's context can be divided into internal and external components. External context refers to the social, economic, political, and competitive environments in which an organization operates. The internal context refers to the structure, culture, resources, capabilities, and politics of an organization. The content covers the specific areas of the transformation under examination. In an EHR implementation, these are the EHR system itself (both hardware and software), the work processes, and everything related to these (e.g. social conditions). The process dimension concerns the processes of change, made up of the plans, actions, reactions, and interactions of the stakeholders, rather than work processes in general. It is important to note that Pettigrew [13] does not see strategic change as a rational analytical process but rather as an iterative, continuous, multilevel process. This highlights that the outcome of an organizational change will be determined by the context, content, and process of that change. The framework with its three categories, shown in Figure 1, illustrates the conceptual model used to categorize the findings of this systematic literature review.

In the literature, several terms are used to refer to electronic medical information systems. In this article, the term Electronic Health Record (EHR) is used throughout. Commonly used terms identified by ISO (the International Organization for Standardization) [16] plus another not identified by ISO are outlined below and used in our search. ISO considers Electronic Health Record (EHR) to be an overall term for " $a$ repository of information regarding the health status of a subject of care, in computer processable form" [16], p. 13. ISO uses different terms to describe various types of EHRs. These include Electronic Medical Record (EMR), which is similar to an EHR but restricted to the medical domain. The terms Electronic Patient Record (EPR) and Computerized Patient Record (CPR) are also identified. Häyrinen et al. [17] view both terms as having the same meaning and referring to a system that contains clinical information from a particular hospital. Another term seen is Electronic Healthcare Record (EHCR) which refers to a system that contains all the available health information on a patient [17] 


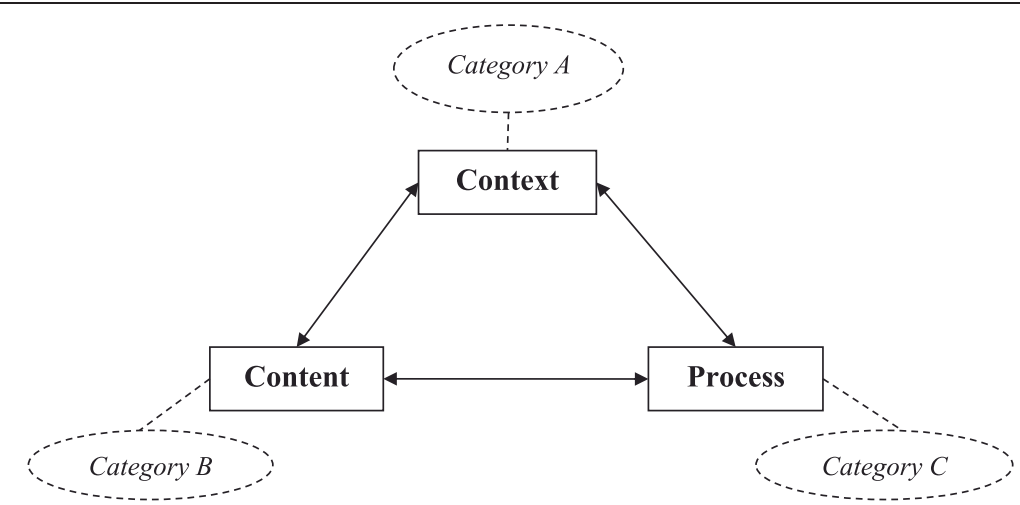

Figure 1 Pettigrew's framework [13] and the corresponding categories.

and can thus be seen as synonymous with EHR [16]. A term often found in the literature is Computerized Physician Order Entry (CPOE). Although this term is not mentioned by ISO [16] or by Häyrinen et al. [17], we included CPOE for three reasons. First, it is considered by many to be a key hospital-wide function of an EHR system e.g. $[8,18]$. Second, from a preliminary analysis of our initial results, we found that, from the perspective of the implementation process, comparable issues and factors emerged from both CPOEs and EHRs. Third, the implementation of a comprehensive electronic medical record requires physicians to make direct order entries [19]. Kaushal et al. define a CPOE as " $a$ variety of computer-based systems that share the common features of automating the medication ordering process and that ensure standardized, legible, and complete orders" [18], p. 1410. Other terms found in the literature were not included in this review as they were considered either irrelevant or too broadly defined. Examples of such terms are Electronic Client Record (ECR), Personal Health Record (PHR), Digital Medical Record (DMR), Health Information Technology (HIT), and Clinical Information System (CIS).

\section{Methods}

\section{Search strategies}

In order for a systematic literature review to be comprehensive, it is essential that all terms relevant to the aim of the research are covered in the search. Further, we need to include relevant synonyms and related terms, both for electronic medical information systems and for hospitals. By adding an * to the end of a term, the search engines pick out other forms, and by adding " " around words one ensures that only the complete term is searched for. Further, by including a ? as a wildcard character, every possible combination is included in the search.

The search used three categories of keywords. The first category included the following terms as approximate synonyms for hospital: "hospital", "healthcare", and "clinic". The second category concerned implementation and included the term "implement"*. For the third category, electronic medical information systems, the following search terms were used: "Electronic Health Record"", "Electronic Patient Record"", "Electronic Medical Record"", "Computeri?ed Patient Record"*, "Electronic Healthcare Record"”, "Computeri?ed Physician Order Entry".

This relatively large set of keywords was necessary to ensure that articles were not missed in the search, and required a large number of search strategies to cover all those keywords. As we were seeking papers about the implementation of electronic medical information systems in hospitals, the search strategies included the terms shown in Table 1.

The following three search engines were chosen based on their relevance to the field and their accessibility by the researcher: Web of knowledge, EBSCO, and The Cochrane Library. Most search engines use several databases but not all of them were relevant for this research as they serve a wide range of fields. Appendix A provides an overview of the databases used. The reference lists included in articles that met the selection criteria were checked for other possibly relevant studies that had not been identified in the database search.

The articles identified from the various search strategies had to be academic peer-reviewed articles if they were to be included in our review. Further, they were assessed and had to satisfy the following criteria to be included: (1) written in English, (2) full text available online, (3) based on primary empirical data, (4) focused on hospital-wide EHR implementation, and (5) meeting established quality criteria. A long list of abstracts was generated, and all of them were independently reviewed by two of the authors. They independently reviewed the abstracts, eliminated duplicates and shortlisted abstracts for detailed review. When opinions differed, a final decision over inclusion was made following a discussion between the researchers. 
Table 1 Overview of the search strategies

\begin{tabular}{|c|c|}
\hline Search strategy & Terms used $^{* *}$ \\
\hline [1] & "Electronic Health Record" + implement* + hospital* \\
\hline [2] & $\begin{array}{l}\text { "Electronic Health Record*" }+ \text { implement* + "health } \\
\text { care" }^{\text {ing }}\end{array}$ \\
\hline [3] & "Electronic Health Record" ${ }^{*}$ implement ${ }^{*}+$ clinic $^{*}$ \\
\hline [4] & "Electronic Patient Record*" + implement* + hospital* \\
\hline [5] & $\begin{array}{l}\text { "Electronic Patient Record*" }+ \text { implement* + "health } \\
\text { care" }\end{array}$ \\
\hline [6] & "Electronic Patient Record*" + implement ${ }^{*}+$ clinic $^{*}$ \\
\hline [7] & "Electronic Medical Record" + implement* + hospital" \\
\hline [8] & $\begin{array}{l}\text { "Electronic Medical Record*" + implement* + "health } \\
\text { care" }\end{array}$ \\
\hline [9] & "Electronic Medical Record*" + implement* + clinic $^{*}$ \\
\hline [10] & $\begin{array}{l}\text { "Computeri?ed Patient Record*" + implement* + } \\
\text { hospital* }\end{array}$ \\
\hline [11] & $\begin{array}{l}\text { "Computeri?ed Patient Record*" }+ \text { implement* }+ \\
\text { "health care" }\end{array}$ \\
\hline [12] & "Computeri?ed Patient Record*" + implement* + clinic $^{*}$ \\
\hline [13] & $\begin{array}{l}\text { "Electronic Health Care Record*" + implement* + } \\
\text { hospital* }\end{array}$ \\
\hline [14] & $\begin{array}{l}\text { "Electronic Health Care Record*" + implement* }+ \\
\text { "health care" }\end{array}$ \\
\hline [15] & $\begin{array}{l}\text { "Electronic Health Care Record }{ }^{*} \text { + implement* } \\
\text { clinic* }^{*}\end{array}$ \\
\hline [16] & $\begin{array}{l}\text { "Computeri?ed Physician Order Entry" + implement* } \\
+ \text { hospital* }\end{array}$ \\
\hline [17] & $\begin{array}{l}\text { "Computeri?ed Physician Order Entry" + implement* } \\
+ \text { "health care" }\end{array}$ \\
\hline [18] & $\begin{array}{l}\text { "Computeri?ed Physician Order Entry" + implement* } \\
+ \text { clinic* }\end{array}$ \\
\hline
\end{tabular}

**As suggested by the referees of this paper, we also used the terms "introduc*" (instead of "implement") and "provider" (instead of physician, as part of CPOE). Each of these two searches yielded one additional article.

\section{Data analysis}

The quality of the articles that survived this filtering was assessed by the first two authors using the Standard Quality Assessment Criteria for Evaluating Primary Research Papers [18]. In other words, the quality of the articles was jointly assessed by evaluating whether specific criteria had been addressed, resulting in a rating of 2 (fully addressed), 1 (partly addressed), or 0 (not addressed) for each criteria. Different questions are posed for qualitative and quantitative research and, in the event of a mixed-method study, both questionnaires were used. Papers were included if they received at least half of the total possible points, admittedly a relatively liberal cut-off point given comments in the Standard Quality Assessment Criteria for Evaluating Primary Research Papers [20].

The next step was to extract the findings of the reviewed articles and to analyze these with the aim of reaching general findings on the implementation of EHR systems in hospitals. Categorizing these general findings can increase clarity. The earlier introduced conceptual model, based on Pettigrew's framework for understanding strategic change, includes three categories: context (A), content (B), and process (C). As our review is specifically aimed at identifying findings related to the implementation process, possible motives for introducing such a system, as well as its effects and outcomes, are outside its scope. The authors held frequent discussions between themselves to discuss the meaning and the categorization of the general findings.

\section{Results}

\section{Paper selection}

Applying the 18 search strategies listed in Table 1 with the various search engines resulted in 364 articles being identified. The searches were carried out on 12 March 2013 for search strategies 1-15 and on 18 April 2013 for search strategies 16-18. The latter three strategies were added following a preliminary analysis of the first set of results which highlighted several other terms and descriptions for information technology in health care. Not surprisingly, many duplicates were included in the 364 articles, both within and between search engines. Using the Refworks functions for identifying exact and close duplicates, 160 duplicates were found. However, this procedure did not identify all the duplicates present and the second author carried out a manual check that identified an additional 23 duplicates. When removing duplicates, we retained the link to the first search engine that identified the article and, as the Web of Knowledge was the first search engine used, most articles appear to have stemmed from this search engine. This left 181 different articles which were screened on title and abstract to check whether they met the selection criteria. When this was uncertain, the contents of the paper were further investigated. This screening resulted in just 13 articles that met all the selection criteria. We then performed two additional checks for completeness. First, checking the references of these articles identified another nine articles. Second, as suggested by the referees of this paper, we also used the term "introduc*" instead of "implement", together with the other two original categories of terms, and the term "provider" instead of "physician", as part of CPOE. Each of these two searches identified one additional article (see Table 1). Of these resulting 24 articles, two proved to be almost identical so one was excluded, resulting in 23 articles for a final quality assessment.

The results of the quality assessment can be found in Appendix B. The results show that two articles failed to 
meet the quality threshold and so 21 articles remained for in-depth analysis. Figure 2 displays the steps taken in this selection procedure.

To provide greater insight into the context and nature of the 21 remaining articles, an overview is provided in Table 2. All the studies except one were published after 2000. This reflects the recent increase in effort to implement organization-wide information systems, such as EHR systems, and also increasing incentives from governments to make use of EHR systems in hospitals. Of the 21 studies, 14 can be classified as qualitative, 6 as quantitative, and 1 as a mixed-method study. Most studies were conducted in the USA, with eight in various European countries. Teaching and non-teaching hospitals are almost equally the subject of inquiry, and some researchers have focused on specific types of hospitals such as rural, critical access, or psychiatric hospitals. Ten of the articles were in journals with a five-year impact factor in the Journal Citation Reports 2011 database. There is a huge difference in the number of citations but one should never forget that newer studies have had fewer opportunities to be cited.

\section{Theoretical perspectives of reviewed articles}

In research, it is common to use theoretical frameworks when designing an academic study [41]. Theoretical frameworks provide a way of thinking about and looking at the subject matter and describe the underlying assumptions about the nature of the subject matter [42]. By building on existing theories, research becomes focused

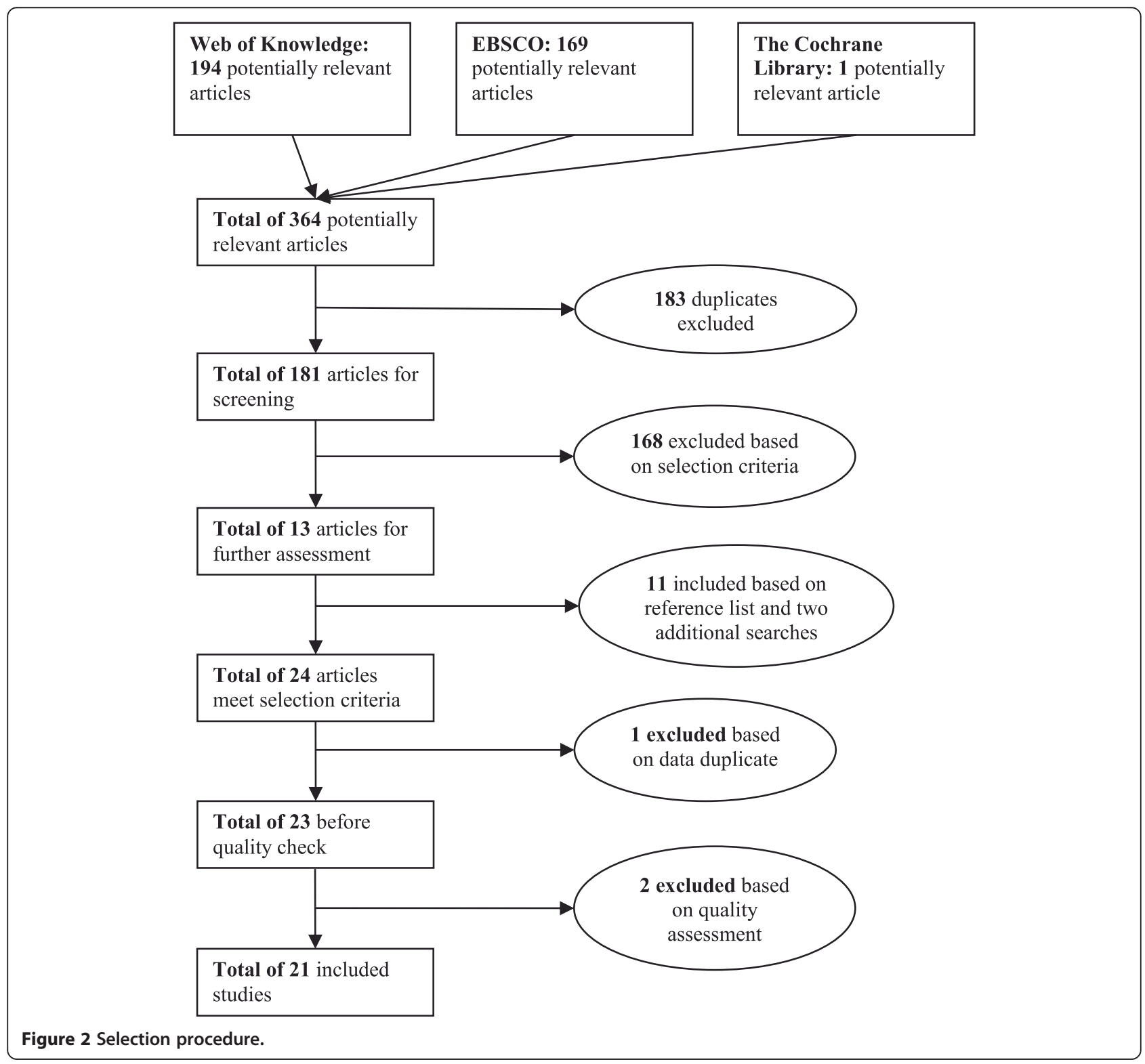


Table 2 Overview of studies included in the systematic literature review

\begin{tabular}{|c|c|c|c|c|c|c|c|c|}
\hline Author & Country/region & $\begin{array}{l}\text { Main objective } \\
\text { of study }\end{array}$ & $\begin{array}{l}\text { Type of } \\
\text { research }\end{array}$ & $\begin{array}{l}\text { Data } \\
\text { collection }\end{array}$ & $\begin{array}{l}\text { Participants (sample } \\
\text { size, response rate) }\end{array}$ & $\begin{array}{l}\text { Hospital } \\
\text { type }\end{array}$ & $\begin{array}{l}\text { Impact } \\
\text { factor }\end{array}$ & Citations $^{* *}$ \\
\hline Aarts et al. [21] & The Netherlands & $\begin{array}{l}\text { To examine the three } \\
\text { theoretical aspects (social } \\
\text { process, emergent change, } \\
\text { socially negotiated judgments) } \\
\text { to understand the implementation } \\
\text { process. }\end{array}$ & Qualitative & $\begin{array}{l}\text { Semi-structured } \\
\text { interviews, observations, } \\
\text { document analysis }\end{array}$ & $\begin{array}{l}10 \text { members of the project } \\
\text { team from different disciplines }\end{array}$ & Teaching hospital & 4.329 & 194 \\
\hline Aarts \& Berg [22] & The Netherlands & $\begin{array}{l}\text { To understand the outcomes } \\
\text { of CPOE implementation using } \\
\text { a heuristic model and to identify } \\
\text { factors that determine successful } \\
\text { implementation. }\end{array}$ & Qualitative & $\begin{array}{l}\text { Open interviews, } \\
\text { observations, } \\
\text { document analysis }\end{array}$ & $\begin{array}{l}25 \text { interviews with project } \\
\text { team members, physicians, } \\
\text { nurses, technical and clerical } \\
\text { personnel }\end{array}$ & $\begin{array}{l}\text { Teaching hospital \& } \\
\text { regional hospital }\end{array}$ & 1.090 & 47 \\
\hline Ash et al. [23] & $\begin{array}{l}\text { USANirginia, } \\
\text { Washington, } \\
\text { California }\end{array}$ & $\begin{array}{l}\text { To find out how some hospitals } \\
\text { had successfully implemented POE. }\end{array}$ & $\begin{array}{l}\text { Quantitative } \\
\text { and Qualitative }\end{array}$ & $\begin{array}{l}\text { Survey, semi-structured } \\
\text { interviews, focus groups, } \\
\text { observations }\end{array}$ & $\begin{array}{l}\text { Quantitative: } 1000 \text { hospitals } \\
\text { (37\% response rate) Qualitative: } \\
32 \text { interviews with physicians, } \\
\text { nurses, pharmacists, IT-staff, } \\
\text { administrators }\end{array}$ & $\begin{array}{l}\text { quantitative : } 1000 \\
\text { hospitals qualitative: } \\
2 \text { teaching hospitals, } 2 \\
\text { community hospitals }\end{array}$ & - & 37 \\
\hline Ash et al. [24] & $\begin{array}{l}\text { USANirginia, } \\
\text { Washington, } \\
\text { California }\end{array}$ & $\begin{array}{l}\text { To describe perceptions of POE } \\
\text { held by diverse professionals at } \\
\text { both teaching and nonteaching } \\
\text { sites where POE has been } \\
\text { successfully implemented. }\end{array}$ & Qualitative & $\begin{array}{l}\text { Semi-structured } \\
\text { interviews, focus groups, } \\
\text { observations }\end{array}$ & $\begin{array}{l}\text { Physicians, administrators, and } \\
\text { information technology } \\
\text { personnel }\end{array}$ & $\begin{array}{l}2 \text { teaching hospitals, } \\
2 \text { community hospitals }\end{array}$ & 4.329 & 160 \\
\hline Boyer et al. [25] & France & $\begin{array}{l}\text { To examine health care professionals' } \\
\text { opinions on the critical events } \\
\text { (opportunities and barriers) } \\
\text { surrounding EMR implementation }\end{array}$ & Qualitative & $\begin{array}{l}\text { Semi-structured } \\
\text { interviews }\end{array}$ & $\begin{array}{l}115 \text { psychiatrists, nurses, } \\
\text { psychologists and social } \\
\text { assistants, secretaries and } \\
\text { administrative professionals }\end{array}$ & $\begin{array}{l}\text { Psychiatric teaching } \\
\text { hospital }\end{array}$ & 0.420 & 0 \\
\hline Cresswell et al. [26] & United Kingdom & $\begin{array}{l}\text { To explore how EHR has shaped } \\
\text { professional practice and what } \\
\text { consequences these changes had } \\
\text { for organizational functioning, } \\
\text { record keeping and patient care. }\end{array}$ & Qualitative & $\begin{array}{l}\text { Semi-structured } \\
\text { interviews, observations, } \\
\text { documents }\end{array}$ & $\begin{array}{l}66 \text { users and other hospital } \\
\text { staff, }\end{array}$ & $\begin{array}{l}3 \text { hospitals, } 1 \text { acute } \\
\text { setting, } 1 \text { community } \\
\text { and mental health. }\end{array}$ & - & 13 \\
\hline Ford et al. [27] & USA & $\begin{array}{l}\text { To assess complete versus } \\
\text { incomplete HIT implementation } \\
\text { levels among U.S. hospitals in } \\
\text { light of the various technology } \\
\text { adoption strategies employed } \\
\text { and to discuss the implications } \\
\text { with respect to meaningful use } \\
\text { for hospitals that have adopted } \\
\text { the different HIT strategies. }\end{array}$ & Quantitative & Survey & 1,814 hospitals & All kinds of hospitals & - & 13 \\
\hline Gastaldi et al. [28] & Italy & $\begin{array}{l}\text { To examine how hospital } \\
\text { performance can be improved } \\
\text { by enhancing and balancing } \\
\text { knowledge exploration and } \\
\text { exploitation capabilities through } \\
\text { the development of an EMR. }\end{array}$ & Qualitative & Interviews, archival data & $\begin{array}{l}27 \text { interviews in three } \\
\text { hospitals }\end{array}$ & $\begin{array}{l}3 \text { hospitals, } 2 \text { teaching } \\
\text { and } 1 \text { non-teaching }\end{array}$ & - & 2 \\
\hline
\end{tabular}


Table 2 Overview of studies included in the systematic literature review (Continued)

\begin{tabular}{|c|c|c|c|c|c|c|c|c|}
\hline $\begin{array}{l}\text { Houser \& } \\
\text { Johnson [29] }\end{array}$ & USA/Alabama & $\begin{array}{l}\text { 1. To determine the status of } \\
\text { implementation of EHRs in } \\
\text { hospitals in the state of Alabama; } \\
\text { 2. To assess the factors that are } \\
\text { driving the decision making for } \\
\text { implementation of EHRs; and } 3 \text {. } \\
\text { To assess the perceptions of HIM } \\
\text { professionals of the benefits, } \\
\text { barriers, and risks that are } \\
\text { associated with implementation } \\
\text { of EHRs. }\end{array}$ & Quantitative & Survey & $\begin{array}{l}131 \text { directors in health } \\
\text { information management, 69\% } \\
\text { response rate }\end{array}$ & $\begin{array}{l}\text { Members of the } \\
\text { Alabama Hospital } \\
\text { Association }\end{array}$ & - & 19 \\
\hline Jaana et al. [30] & USA/lowa & $\begin{array}{l}\text { To present an overview of clinical } \\
\text { information systems (IS) in hospitals } \\
\text { and to analyze the level of electronic } \\
\text { medical records (EMR) implementation } \\
\text { in relation to clinical IS capabilities } \\
\text { and organizational characteristics. }\end{array}$ & Quantitative & Survey & $\begin{array}{l}116 \mathrm{CEOs} \text { or } \mathrm{ClOs}, 84 \% \\
\text { response rate }\end{array}$ & Nonfederal hospitals & - & 3 \\
\hline Katsma et al. [31] & The Netherlands & $\begin{array}{l}\text { To contribute to the developments } \\
\text { in method engineering, which } \\
\text { promises a better participation } \\
\text { of the user. }\end{array}$ & Qualitative & Interviews & $\begin{array}{l}12 \text { people, being supported } \\
\text { sponsor, process owner or } \\
\text { key-user }\end{array}$ & 4 hospitals & - & 4 \\
\hline Ovretveit et al. [32] & Sweden & $\begin{array}{l}\text { To describe and assess an } \\
\text { implementation in one hospital } \\
\text { and analyze this in relation to } \\
\text { factors suggested by previous } \\
\text { research to be important for } \\
\text { successful implementation as } \\
\text { well as in relation to a published } \\
\text { USA case study, which used } \\
\text { similar methods. }\end{array}$ & Qualitative & Interviews & $\begin{array}{l}30 \text { persons, project leaders, } \\
\text { supervisors, heads of division } \\
\text { and clinics, instructor, nurses, } \\
\text { physicians, and doctor secretary }\end{array}$ & Teaching hospital & 2.480 & 86 \\
\hline Poon et al. [33] & USA & $\begin{array}{l}\text { To provide more insight into the } \\
\text { challenges to CPOE implementation. }\end{array}$ & Qualitative & Interviews & $\begin{array}{l}52 \text { CIOs/CFOs/CMOs and } \\
\text { senior managers from } 26 \\
\text { hospitals ( } 46 \text { hospitals were } \\
\text { contacted: } 57 \% \text { response rate }\end{array}$ & $\begin{array}{l}\text { Both teaching and } \\
\text { non-teaching hospitals }\end{array}$ & 3.748 & 269 \\
\hline Rivard et al. [34] & Canada & $\begin{array}{l}\text { To propose a substantive theory - } \\
\text { a theory developed for a particular } \\
\text { area of inquiry (Gregor, 2006) - to } \\
\text { provide an organizational culture-based } \\
\text { explanation of the level of difficulty of } \\
\text { a CIS implementation and of the } \\
\text { implementation practices that can } \\
\text { help reduce the level of difficulty } \\
\text { of this process. }\end{array}$ & Qualitative & Interviews & $\begin{array}{l}43 \text { people, physicians, nurses, } \\
\text { and administrators }\end{array}$ & $\begin{array}{l}3 \text { hospitals, } 2 \text { teaching } \\
\text { and } 1 \text { community } \\
\text { hospital }\end{array}$ & 2.654 & 9 \\
\hline Scott et al. [35] & USA/Hawaii & $\begin{array}{l}\text { To examine users' attitudes to } \\
\text { implementation of an electronic } \\
\text { medical record system in Kaiser }\end{array}$ & Qualitative & Interviews & $\begin{array}{l}26 \text { senior physicians, managers } \\
\text { and project team members }\end{array}$ & One hospital, 4 clinics & 13.511 & 174 \\
\hline
\end{tabular}


Table 2 Overview of studies included in the systematic literature review (Continued)

\begin{tabular}{|c|c|c|c|c|c|c|c|c|}
\hline Simon et al. [36] & USA/Massachusetts & $\begin{array}{l}\text { To identify attitudes, behaviors and } \\
\text { experiences that would constitute } \\
\text { useful lessons for other hospitals } \\
\text { embarking on CPOE implementation }\end{array}$ & Qualitative & Interviews, observations & $\begin{array}{l}24 \text { physicians, nurses and } \\
\text { pharmacists }\end{array}$ & 5 community hospitals & - & 2 \\
\hline Takian et al. [37] & England & $\begin{array}{l}\text { To report on a case study of the } \\
\text { implementation of an EHR (RiO) into } \\
\text { a mental health setting delivered } \\
\text { though the NPfIT and analyzed } \\
\text { using our adapted 'socio technical } \\
\text { changing framework'. }\end{array}$ & Qualitative & $\begin{array}{l}\text { Interviews, observations, } \\
\text { document analysis }\end{array}$ & $\begin{array}{l}48 \text { interviews with senior } \\
\text { managers, implementation } \\
\text { team members, healthcare } \\
\text { practitioners }\end{array}$ & Mental health hospital & 2.254 & 0 \\
\hline Ward et al. [38] & USA & $\begin{array}{l}\text { To examine the impact of clinical } \\
\text { information system implementation } \\
\text { on nurses' perceptions of workflow } \\
\text { and patient care throughout the } \\
\text { implementation process. }\end{array}$ & Quantitative & Survey & 705 nurses & Rural hospital & - & 3 \\
\hline Ward et al. [39] & USA & $\begin{array}{l}\text { To examine staff perceptions of } \\
\text { patient care quality and the } \\
\text { processes before and after } \\
\text { implementation of a comprehensive } \\
\text { clinical information system (CIS) in } \\
\text { critical access hospitals (CAHs). }\end{array}$ & Quantitative & Survey & $\begin{array}{l}840 \text { nurses, providers, and } \\
\text { other clinical staff }\end{array}$ & Critical access hospitals & 2.540 & 0 \\
\hline Weir et al. [19] & USA/Utah & $\begin{array}{l}\text { To identify factors that discriminate } \\
\text { successful from non-successful } \\
\text { implementation of OE/RR } 2.5 \text { in } \\
\text { order to prepare for the next version. }\end{array}$ & Quantitative & Survey & $\begin{array}{l}52 \text { medical administration staff, } \\
\text { administrators, support staff, } \\
\text { users (ward clerks, physicians, } \\
\text { and nurses), and physician } \\
\text { opinion leaders ( } 92 \text { received } \\
\text { survey, thus } 57 \% \text { response rate) }\end{array}$ & 6 hospitals & - & 29 \\
\hline $\begin{array}{l}\text { Yoon-Flannery } \\
\text { et al. [40] }\end{array}$ & USA/New York & $\begin{array}{l}\text { To determine pre-implementation } \\
\text { perspectives of institutional, practice } \\
\text { and vendor leadership regarding } \\
\text { best practice for implementation } \\
\text { of two ambulatory electronic health } \\
\text { records (EHRs) at an academic } \\
\text { institution. }\end{array}$ & Qualitative & Interviews & $\begin{array}{l}31 \text { interviews with institutional } \\
\text { leaders, practice leaders and } \\
\text { vendor leaders. }\end{array}$ & Teaching hospital & - & 25 \\
\hline
\end{tabular}

*The 5-year impact factor based on the Journal Citation Reports 2011 is used in this table.

**The number of citations is identified using scholar.google.nl. 
in aiming to enrich and extend the existing knowledge in that particular field [42]. To provide a more thorough understanding of the selected articles, their theoretical frameworks, if present, are outlined in Table 3.

It is striking that no specific theoretical frameworks have been used in the research leading to 13 of the 21 selected articles. Most articles simply state their objective as gaining insight into certain aspects of EHR implementation (as shown in Table 1) and do not use a particular theoretical approach to identify and categorize findings. As such, these articles add knowledge to the field of EHR implementation but do not attempt to extend existing theories.
Aarts et al. [21] introduce the notion of the sociotechnical approach: emphasizing the importance of focusing both on the social aspects of an EHR implementation and on the technical aspects of the system. Using the concept of emergent change, they argue that an implementation process is far from linear and predictable due to the contingencies and the organizational complexity that influences the process. A sociotechnical approach and the concept of emergent change are also included in the theoretical framework of Takian et al. [37]. Aarts et al. [21] elaborate on the sociotechnical approach when stating that the fit between work processes and the information technology determines the success of the

Table 3 Overview of the theoretical frameworks used in the included studies

\begin{tabular}{|c|c|}
\hline Author & Theoretical framework \\
\hline Aarts et al. [21] & $\begin{array}{l}\text { Three theoretical aspects: 1) sociotechnical approach, 2) emergent change with an unpredictable outcome, } \\
\text { and 3) "success" and "failure" are socially negotiated judgments and is determined by the fit between work } \\
\text { processes and information technology. }\end{array}$ \\
\hline Aarts \& Berg [22] & $\begin{array}{l}\text { A model on success or failure of information systems with four variables: (1) information system, (2) support } \\
\text { base, (3) medical work practices, and (4) hospital organization. Successful implementation of an information } \\
\text { system (1) is defined as the capability to create a support base (2) for the change of (medical) work practices (3) } \\
\text { induced by the system (4). }\end{array}$ \\
\hline Ash et al. [23] & None \\
\hline Ash et al. [24] & None \\
\hline Boyer et al. [25] & None \\
\hline Cress-well et al. [26] & $\begin{array}{l}\text { Study draws on Actor-Network Theory, which helps to investigate how the centrally procured EHR } \\
\text { has plays an active role in shaping social relationships. }\end{array}$ \\
\hline Ford et al. [27] & HIT adoption strategies: (1) Single-vendor strategy, (2) Best of Breed strategy, and (3) Best of Suite strategy. \\
\hline Gastaldi et al. [28] & $\begin{array}{l}\text { The notion that the capability of any organization to create sustainable organizational value not only resides } \\
\text { in the ownership of knowledge assets guaranteeing the present competitive advantage (knowledge } \\
\text { exploitation), but also in the ability to understand and govern the continuous development of knowledge } \\
\text { assets necessary to renew its organizational capabilities (knowledge exploitation). }\end{array}$ \\
\hline Houser \& Johnson [29] & None \\
\hline Jaana et al. [30] & None \\
\hline Katsma et al. [31] & $\begin{array}{l}\text { IT implementation success is determined by quality (relevance) times acceptation (participation). Relevance } \\
\text { is defined as the degree to which the user expects that the IT system will solve his problems or help to } \\
\text { realize his actually relevant goals. Participation of employees is perceived to increase their acceptation of } \\
\text { the IT system. Effectiveness of participation is moderated by organizational receptiveness, individual ego } \\
\text { development, and knowledge availability. }\end{array}$ \\
\hline Ovretveit et al. [32] & None \\
\hline Poon et al. [33] & None \\
\hline Rivard et al. [34] & $\begin{array}{l}\text { A culture-based explanation of the level of difficulty of a CIS implementation, using an integration perspective } \\
\text { (basic assumptions are shared among the members of the collective), a differentiation perspective (subgroups } \\
\text { within a collective have inconsistent interpretations), and a fragmentation perspective (members within a } \\
\text { collective sometimes manifest multiple interpretations, irrespective their subgroup). }\end{array}$ \\
\hline Scott et al. [35] & None \\
\hline Simon et al. [36] & None \\
\hline Takian et al. [37] & A sociotechnical framework as identified by Aarts et al. (2004), underscoring the emerging nature of change. \\
\hline Ward et al. [38] & None \\
\hline Ward et al. [39] & None \\
\hline Weir et al. [19] & None \\
\hline Yoon-Flannery et al. [40] & None \\
\hline
\end{tabular}


implementation. Aarts and Berg [22] introduce a model of success or failure in information system implementation. They see creating synergy among the medical work practices, the information system, and the hospital organization as necessary for implementation, and argue that this will only happen if sufficient people accept a change in work practices. Cresswell et al.'s study [26] is also influenced by sociotechnical principles and draws on Actor-Network Theory. Gastaldi et al. [28] perceive Electronic Health Records as knowledge management systems and question how such systems can be used to develop knowledge assets. Katsma et al. [31] focus on implementation success and elaborate on the notion that implementation success is determined by system quality and acceptance through participation. As such, they adopt more of a social view on implementation success rather than a sociotechnical approach. Rivard et al. [34] examine the difficulties in EHR implementation from a cultural perspective. They not only view culture as a set of assumptions shared by an entire collective (an integration perspective) but also expect subcultures to exist (a differentiation perspective), as well as individual assumptions not shared by a specific (sub-) group (fragmentation perspective). Ford et al. [27] focus on an entirely different topic and investigate the IT adoption strategies of hospitals using a framework that identifies three strategies. These are the single-vendor strategy (in which all IT is purchased from a single vendor), the best-of-breed strategy (integrating IT from multiple vendors), and the best-of-suit strategy (a hybrid approach using a focal system from one vendor as the basis plus other applications from other vendors).

To summarize, the articles by Aarts et al. [21], Aarts and Berg [22], Cresswell et al. [26], and Takian et al. [37] apply a sociotechnical framework to focus their research. Gastaldi et al. [28] see EHRs as a means to renew organizational capabilities. Katsma et al. [31] use a social framework by focusing on the relevance of an IT system as perceived by the user and the participation of users in the implementation process. Rivard et al. [34] analyze how organizational cultures can be receptive to EHR implementation. Ford et al. [27] look at adoption strategies, leading them to focus on the selection procedure for Electronic Health Records. The 13 other studies did not use an explicit theoretical lens in their research.

\section{Implementation-related findings}

The process of categorization started by assessing whether a specific finding from a study should be placed in Category A, B, or C. Thirty findings were placed in Category A (context), 31 in Category B (content), and 66 in Category $C$ (process). Comparing and combining the specific findings resulted in several general findings within each category. The general findings are each given a code (category character plus number) and the related code is indicated alongside each specific finding in Appendix C. Findings that were only seen in one article, and thus were lacking support, were discarded.

\section{Category A - context}

The context category of an EHR implementation process includes both internal variables (such as resources, capabilities, culture, and politics) and external variables (such as economic, political, and social variables). Six general findings were identified, all but one related to internal variables. An overview of the findings and corresponding articles can be found in Table 4. The lack of general findings related to external variables reflects our decision to exclude the underlying reasons (e.g. political or social pressures) for implementing an EHR system from this review. Similarly, internal findings related to aspects such as perceived financial benefits or improved quality of care, are outside our scope.

\section{A1: Large (or system-affiliated), urban, not-for-profit, and teaching hospitals are more likely to have implemented an EHR system due to having greater financial capabilities, a greater change readiness, and less focus on profit}

The research reviewed shows that larger or systemaffiliated hospitals are more likely to have implemented an EHR system, and that this can be explained by their easier access to the large financial resources required. Larger hospitals have more financial resources than smaller hospitals [30] and system-affiliated hospitals can share costs [27]. Hospitals situated in urban areas more often have an EHR system than rural hospitals, which is attributed to less knowledge of EHR systems and less support from medical staff in rural hospitals [29]. The fact that not-for-profit hospitals more often have an EHR system fully implemented and teaching hospitals slightly more often than private hospitals is attributed to the latter's more wait-and-see approach and the more progressive change-ready nature of public and teaching hospitals [27,32].

\section{A2: EHR implementation requires the selection of a mature vendor who is committed to providing a system that fits the hospital's specific needs}

Although this finding is not a great surprise, it is relevant to discuss it further. A hospital selecting its own vendor can ensure that the system will match the specific needs of that hospital [32]. Further, it is important to deal with a vendor that has proven itself on the EHR market with mature and successful products. The vendor must also be able to identify hospital workflows and adapt its product accordingly, and be committed to a long-term trusting relationship with the hospital [33]. With this in mind, the initial price of the system 
Table 4 Category A - Context findings

\begin{tabular}{lcc}
\hline General finding & Finding code & Article numbers \\
\hline $\begin{array}{l}\text { Large (or system-affiliated), urban, not-for-profit, and teaching hospitals are more likely to have } \\
\text { implemented an EHR system due to having greater financial capabilities, a greater change }\end{array}$ & A1 \\
readiness, and less focus on profit. & A2 & $27 / 29 / 30 / 32$ \\
$\begin{array}{l}\text { EHR implementation requires the selection of a mature vendor who is committed to providing } \\
\text { a system that fits the hospital's specific needs. }\end{array}$ & A3 \\
$\begin{array}{l}\text { The presence of hospital staff with previous experience of Health Information Technology increases } \\
\text { the likelihood of EHR implementation as less uncertainty is experienced by the end-users. }\end{array}$ & A4 \\
$\begin{array}{l}\text { An organizational culture that supports collaboration and teamwork fosters EHR implementation } \\
\text { success because trust between employees is higher. }\end{array}$ & A5 \\
$\begin{array}{l}\text { EHR implementation is most likely in an organization with little bureaucracy and considerable } \\
\text { flexibility as changes can be rapidly made. }\end{array}$ & A6 \\
EHR system implementation is difficult because cure and care activities must be ensured at all times. & $28 / 32 / 33$ \\
\hline
\end{tabular}

should not be the overriding consideration: the organization should be willing to avoid purely cost-oriented vendors [28], as costs soon mount if problems arise.

A3: The presence of hospital staff with previous experience of health information technology increases the likelihood of EHR implementation as less uncertainty is experienced by the end-users

In order to be able to work with an EHR system, users must be capable of using information technology such as computers and have adequate typing skills [19,32]. Knowledge of, and previous experience with, EHR systems or other medical information systems reduces uncertainty and disturbance for users, and this results in a more positive attitude towards the system [29,32,37,38].

\section{A4: An organizational culture that supports collaboration and teamwork fosters EHR implementation success because trust between employees is higher}

The influence of organizational culture on the success of organizational change is addressed in almost all the popular approaches to change management, as well as in several of the articles in this literature review. Ash et al. $[23,24]$ and Scott et al. [35] highlight that a strong culture with a history of collaboration, teamwork, and trust between different stakeholder groups minimizes resistance to change. Boyer et al. [25] suggest creating a favorable culture that is more adaptive to EHR implementation. However, creating a favorable culture is not necessarily easy: a comprehensive approach including incentives, resource allocation, and a responsible team was used in the example of Boyer et al. [25].

\section{A5: EHR implementation is most likely in an organization with little bureaucracy and considerable flexibility as changes can be rapidly made}

A highly bureaucratic organizational structure hampers change: it slows the process and often leads to inter-departmental conflict [19]. Specifically, appointing a multidisciplinary team to deal with EHR-related issues can prevent conflict and stimulate collaboration [25].

\section{A6: EHR system implementation is difficult because cure and care activities must be ensured at all times}

During the process of implementing an EHR system, it is of the utmost importance that all relevant information is always available [28,34,39]. Ensuring the continuity of quality care while implementing an EHR system is difficult and is an important distinction from many other IT implementations.

\section{Category B - content}

The content of the EHR implementation process consists of the EHR system and the corresponding objectives, assumptions, and complementary services. Table 5 lists the five extracted general findings. These focus on both the hardware and software of the EHR system, and its relation to work practices and privacy.

\section{B1: Creating a fit by adapting both the technology and work practices is a key factor in the implementation of EHR} This finding elaborates on the sociotechnical approach identified in the earlier section on the theories adopted in the articles. Several authors [21,26,31,37] make clear that creating a fit between the EHR system and the existing work practices requires an initial acknowledgement that an EHR implementation is not just a technical project and that existing work practices will change due to the new system. By customizing and adapting the system to meet specific needs, users will become more open to using it $[19,26,28]$.

B2: Hardware availability and system reliability, in terms of speed, availability, and a lack of failures, are necessary to ensure EHR use

In several articles, authors highlight the importance of having sufficient hardware. A system can only be used if it is available to the users, and a system will only be used 
Table 5 Category B - Content findings

\begin{tabular}{lcc}
\hline General finding & Finding code & Article numbers \\
\hline $\begin{array}{l}\text { Creating a fit by adapting both the technology and work practices is a key factor in the } \\
\text { implementation of EHR. }\end{array}$ & B1 & 19/21/26/28/31/37 \\
Hardware availability and system reliability in terms of speed, availability, safety, and a & B3 & 19/24/25/29/30/35/37/40 \\
lack of failures, are necessary to ensure EHR use. & B4 \\
$\begin{array}{l}\text { To ensure EHR implementation, the software needs to be user-friendly with regard to } \\
\text { ease of use, efficiency in use, and functionality. }\end{array}$ & B5 \\
$\begin{array}{l}\text { An EHR implementation should contain adequate safeguards for patient privacy and } \\
\text { Confidentiality. }\end{array}$ & 25/29/37/40 \\
EHR implementations require a vendor who is willing to adapt its product to hospital & $32 / 33$ \\
work processes. & &
\end{tabular}

if it works without problems. Ash et al. [24], Scott et al. [35], and Weir et al. [19] refer to the speed of the system as well as to the availability of a sufficient number of adequate terminals see also [40] in various locations. Systems must be logically structured [29], reliable [32], and provide safe information access [37]. Boyer et al. [25] also mention the importance of technical aspects but add that these are not sufficient for EHR implementation.

\section{B3: To ensure EHR implementation, the software needs to be user-friendly with regard to ease of use, efficiency in use, and functionality}

Some authors distinguish between technical availability and reliability, and the user-friendliness of the software $[19,24,32]$. They argue that it is not sufficient for a system to be available and reliable, it should also be easy and efficient in use, and provide the functionality required for medical staff to give good care. If a system fails to do this, staff will not use the system and will stick to their old ways of working.

\section{B4: An EHR implementation should contain adequate safeguards for patient privacy and confidentiality}

Concerns over privacy and confidentiality are recognized by Boyer et al. [25] and Houser and Johnson [29] and are considered as a barrier to EHR implementation. Yoon-Flannery et al. [40] and Takian et al. [37] also recognize the importance of patient privacy and the need to address this issue by providing training and creating adequate safeguards.

\section{B5: EHR implementation requires a vendor who is willing to adapt its product to hospital work processes}

A vendor must be responsive and enable the hospital to develop its product to ensure a good and usable EHR system [32,33]. By so doing, dependence on the vendor decreases and concerns that arise within the hospital can be addressed [32]. This finding is related to A2 in the sense that an experienced, cooperative, and flexible vendor is needed to deal with the range of interest groups found in hospitals.

\section{Category C - process}

This category refers to the actual process of implementing the EHR system. Variables considered are time, change approach, and change management. In our review, this category produced the largest number of general findings (see Table 6), as might be expected given our focus on the implementation process. EHR implementation often leads to anxiety, uncertainty, and concerns about a possible negative impact of the EHR on work processes and quality. The process findings, including leadership, resource availability, communication and participation are explicitly aimed at overcoming resistance to EHR implementation. These interventions help to create a positive atmosphere of goal directedness, co-creation and partnership.

\section{C1: Due to their influential position, management's active involvement and support is positively associated with EHR implementation, and also counterbalances the physicians' medical dominance}

Several authors note the important role that managers play in EHR implementation. Whereas some authors refer to supportive leadership [19,24], others emphasize that strong and active management involvement is needed [25,32-35]. Strong leadership is relevant as it effectively counterbalances the physicians' medical dominance. For instance, Rivard et al. [34] observe that physicians' medical dominance and the status and autonomy of other health professionals hinder collaboration and teamwork, and that this complicates EHR implementation. Poon et al. [33] acknowledge this aspect and argue for strong leadership in order to deal with the otherwise dominant physicians. They also claim that leaders have to set an example and use the system themselves. At the same time, it is motivating that the implementation is managed by leaders who are recognized by the medical staff, for instance by head nurses and physicians or by former physicians 
Table 6 Category C - Process findings

\begin{tabular}{|c|c|c|}
\hline General finding & Finding code & Article numbers \\
\hline $\begin{array}{l}\text { Due to their influential position, management's active involvement and support is positively } \\
\text { associated with EHR implementation, and also counterbalances the physicians' medical dominance. }\end{array}$ & C1 & $19 / 24 / 25 / 32 / 33 / 34 / 35$ \\
\hline $\begin{array}{l}\text { Participation of clinical staff in the implementation process increases support for and acceptance } \\
\text { of the EHR implementation. }\end{array}$ & $\mathrm{C} 2$ & $19 / 25 / 26 / 28 / 32 / 35 / 36$ \\
\hline Training end-users and providing real-time support is important for EHR implementation success. & $\mathrm{C} 3$ & $19 / 29 / 32 / 36$ \\
\hline $\begin{array}{l}\text { A comprehensive implementation strategy, offering both clear guidance and room for emergent } \\
\text { change, is needed for implementing an EHR system. }\end{array}$ & C4 & $19 / 21 / 25 / 26 / 28 / 31 / 37 / 40 / 36$ \\
\hline $\begin{array}{l}\text { Establishing an interdisciplinary implementation group consisting of developers, members of } \\
\text { the IT department, and end-users fosters EHR implementation success. }\end{array}$ & $\mathrm{C} 5$ & 19/32/36 \\
\hline $\begin{array}{l}\text { Resistance of clinical staff, in particular of physicians, is a major barrier to EHR implementation, } \\
\text { but can be reduced by addressing their concerns. }\end{array}$ & C6 & $22 / 24 / 26 / 28 / 29 / 33 / 36$ \\
\hline C7: Identifying champions among clinical staff reduces resistance. & C7 & $32 / 33 / 36$ \\
\hline $\begin{array}{l}\text { Assigning a sufficient number of staff and other resources to the EHR implementation process } \\
\text { is important in adequately implementing the system. }\end{array}$ & $\mathrm{C} 8$ & 19/26/32/33/36 \\
\hline
\end{tabular}

and nurses [25,33]. Ovretveit et al. [32] argue that it helps the implementation if senior management repeatedly declares the EHR implementation to be of the highest priority and supports this with sufficient financial and human resources. Poon et al. [33] add to this by highlighting that, especially during uncertainties and setbacks, the common vision that guides the EHR implementation has to be communicated to hospital staff. Sufficient human resources include the selection of competent and experienced project leaders who are familiar with EHR implementation. Scott et al. [35] identify leadership styles for different phases: participatory leadership is valued in selection decisions, whereas a more hierarchical leadership style is preferable in the actual implementation.

\section{C2: Participation of clinical staff in the implementation process increases support for and acceptance of the EHR implementation}

Participation of end-users (the clinical staff) generates commitment and enables problems to be quickly solved $[25,26,36]$. Especially because it is very unlikely that the system will be perfect for all, it is important that the clinical staff become the owner, rather than customers, of the system. Clinical staff should participate at all levels and in all steps [19,28,32,36] from initial system selection onwards [35]. Ovretveit et al. [32] propose that this involvement should have an extensive timeframe, starting in the early stages of implementation, when initial vendor requirements are formulated ('consultation before implementation'), through to the beginning of the use phase. Creating multidisciplinary work groups which determine the content of the EHR and the rules regarding the sharing of information contributes to EHR acceptance [25] and ensures realistic approaches acceptable to the clinical staff [36].

\section{C3: Training end-users and providing real-time support is important for EHR implementation success}

Frequently, the end-users of a new EHR system lack experience with the specific EHR system or with EHR systems in general. Although it is increasingly hard to imagine society or workplaces without IT, a large specific system, such as an EHR, still requires considerable training on how to use it properly. The importance of training is often underestimated, and inadequate training will create a barrier to EHR use [19,29]. Consequently, adequate training, of appropriate quantity and quality, must be provided at the right times and locations $[19,32,36]$. Simon et al. [36] add to this the importance of real-time support, preferably provided by peers and super-users.

\section{C4: A comprehensive implementation strategy, offering both clear guidance and room for emergent change, is needed for implementing an EHR system}

Several articles highlight aspects of an EHR implementation strategy. A good strategy facilitates EHR implementation $[19,25]$ and consists of careful planning and preparation [36], a sustainable business plan, effective communication $[28,40]$ and mandatory implementation [19]. Emergent change is perceived as a key characteristic of EHR implementation in complex organizations such as hospitals [21], and this suggests an implementation approach based on a development paradigm [31], which may initially even involve parallel use of paper [26]. The notion of emergent change has been variously applied, including in the theoretical frameworks of Aarts et al. [21] and Katsma et al. [31]. These studies recognize that EHR implementation is relatively unpredictable due to unforeseen contingencies for which one cannot plan. With their emphasis on emergent change with unpredictable outcomes, Aarts et al. [21] make a case for acknowledging 
that unexpected and unplanned contingencies will influence the implementation process. They argue that the changes resulting from these contingencies often manifest themselves unexpectedly and must then be dealt with. Additionally, Takian et al. [37] state that it is crucial to contextualize an EHR implementation so as to be better prepared for unexpected changes.

\section{C5: Establishing an interdisciplinary implementation group consisting of developers, members of the IT department, and end-users fosters EHR implementation success}

In line with the arguments for management support and for the participation of clinical staff, Ovretveit et al. [32], Simon et al. [36] and Weir et al. [19] build a case for using an interdisciplinary implementation group. By having all the direct stakeholders working together, a better EHR system can be delivered faster and with fewer problems.

\section{C6: Resistance of clinical staff, in particular of physicians, is a major barrier to EHR implementation, but can be reduced by addressing their concerns}

Clinical staff's attitude is a crucial factor in EHR implementation [36]. Particularly, the physicians constitute an important group in hospitals. As such, their possible resistance to EHR implementation will form a major barrier [29,33] and may lead to workarounds [26]. Whether physicians accept or reject an EHR implementation depends on their acceptance of their work practices being transformed [22]. The likelihood of acceptance will be increased if implementers address the concerns of physicians [24,28,32,33], but also of other members of clinical staff [36].

\section{C7: Identifying champions among clinical staff reduces resistance}

The previous finding already elaborated on clinical staff resistance and suggested reducing this by addressing their concerns. Another way to reduce their resistance is related to the process of implementation and involves identifying physician champions, typically physicians that are well respected due to their knowledge and contacts [32,33]. Simon et al. [36] emphasize the importance of identifying champions among each stakeholder group. These champions can provide reassurance to their peers.

\section{C8: Assigning a sufficient number of staff and other resources to the EHR implementation process is important in adequately implementing the system}

Implementing a large EHR system requires considerable resources, including human ones. Assigning appropriate people, such as super-users [36] and a sufficient number of them to that process will increase the likelihood of success $[19,32,33,36]$. Further, it is important to have sufficient time and financial resources [26,32]. This finding is also relevant in relation to finding A6 (ensuring good care during organizational change).

These 19 general findings have been identified from the individual findings within the 20 analyzed articles. These findings are all related to one of the three main and interacting dimensions of the framework: six to context, five to content, and eight to process. This identification and explanation of the general findings concludes the results section of this systematic literature review and forms the basis for the discussion below.

\section{Discussion}

This review of the existing academic literature sheds light on the current knowledge regarding EHR implementation. The 21 selected articles all originate from North America or Europe, perhaps reflecting a greater governmental attention to EHR implementation in these regions and, of course, our inclusion of only articles written in English. Two articles were rejected for quality reasons [43,44], see Appendix B. All but one of the selected articles have been published since 2000, reflecting the growing interest in implementing EHR systems in hospitals. Eight articles built their research on a theoretical framework, four of which use the same general lens of the sociotechnical approach [21,22,26,37]. Katsma et al. [31] and Rivard et al. [34] focus more on the social and cultural aspects of EHR implementation, the former on the relevance for, and participation of, users, the latter on three different cultural perspectives. Ford et al. [27] researched adoption strategies for EHR systems and Gastaldi et al. [26] consider them as a means to renew organizational capabilities. It is notable that the other reviewed articles did not use a theoretical framework to analyze EHR implementation and made no attempt to elaborate on existing theories.

A total of 127 findings were extracted from the articles, and these findings were categorized using Pettigrew's framework for strategic change [13] as a conceptual model including the three dimensions of context, content, and process. To ensure a tight focus, the scope of the review was explicitly limited to findings related to the EHR implementation process, thus excluding the reasons for, barriers to, and outcomes of an EHR implementation.

Some of the findings require further interpretation. Contextual finding A1 relates to the demographics of a hospital. One of the assertions is that privately owned hospitals are less likely than public hospitals to invest in an EHR. The former apparently perceive the costs of EHR implementation to outweigh the benefits. This seems remarkable given that there is a general belief that information technology increases efficiency and reduces process costs, so more than compensating for the high initial investments. It is however important to note that the literature on EHR is ambivalent when it comes to efficiency; several authors record a decrease in the efficiency of work 
practices [25,33,35,38], whereas others mention an increase $[29,31]$. Finding A2 is a reminder of the importance of carefully selecting an appropriate vendor, taking into account experience with the EHR market and the maturity of their products rather than, for example, focussing on the cost price of the system. Given the huge investment costs, the price of an EHR system tends to have a major influence on vendor selection, an aspect that is also promoted by the current European tendering regulations that oblige (semi-) public institutions, like many hospitals, to select the lowest bidder, or the bidder that is economically the most preferable [45]. The finding that EHR system implementation is difficult because good medical care needs to be ensured at all times (A6) also deserves mention. Essentially, many system implementations in hospitals are different from IT implementations in other contexts because human lives are at stake in hospitals. This not only complicates the implementation process because medical work practices have to continue, it also requires a system to be reliable from the moment it is launched.

The findings regarding the content of the EHR system (Category B) highlight the importance of a suitable software product. A well-defined selection process of the software package and its associated vendor (discussed in A2) is seen as critical (B5). Selection should be based on a careful requirements analysis and an analysis of the experience and quality of the vendor. An important requirement is a sufficient degree of flexibility to customize and adapt the software to meet the needs of users and the work practices of the hospital (finding B1). At the same time the software product should challenge the hospital to rethink and improve its processes. A crucial condition for the acceptance by the diverse user groups of hospitals is the robustness of the EHR system in terms of availability, speed, reliability and flexibility (B2). This also requires adequate hardware in terms of access to computers, and mobile equipment to enable availability at all the locations of the hospital. Perceived ease of use of the system (B4) and the protection of patients' privacy (B4) are other content factors that can make or break EHR implementation in hospitals.

The findings on the implementation process, our Category $\mathrm{C}$, highlight four aspects that are commonly mentioned in change management approaches as important success factors in organizational change. The active involvement and support of management $(\mathrm{C} 1)$, the participation of clinical staff $(\mathrm{C} 2)$, a comprehensive implementation strategy (C4), and using an interdisciplinary implementation group (C5) correspond with three of the ten guidelines offered by Kanter et al. [46]. These three guidelines are: (1) support a strong leader role; (2) communicate, involve people, and be honest; and (3) craft an implementation plan. As the implementation of an EHR system is an organizational change process it is no surprise that these commonalities are identified in several of the analyzed articles. Three Category $\mathrm{C}$ findings (C2, C6, and $\mathrm{C} 7)$ concern dealing with clinical staff given their powerful positions and potential resistance. Physicians are the most influential medical care providers, and their resistance can delay an EHR implementation [23], lead to at least some of it being dropped [21,22,34], or to it not being implemented at all [33]. Thus, there is ample evidence of the crucial importance of physicians' acceptance of an EHR for it to be implemented. This means that clinicians and other key personnel should be highly engaged and motivated to contribute to EHR. Prompt feedback on requests, and high quality support during the implementation, and an EHR that clearly supports clinical work are key issues that contribute to a motivated clinical staff.

Analyzing and comparing the findings enables us to categorize them in terms of subject matter (see Table 7). By categorizing the findings in terms of subject, and by totaling the number of articles related to the individual findings on that subject, one can deduce how much attention has been given in the literature to the different topics. This analysis highlights that the involvement of physicians in the implementation process, the quality of the system, and a comprehensive implementation strategy are considered the crucial elements in EHR implementation.

Notwithstanding the useful results, this review and analysis has some limitations. Although we carefully developed and executed the search strategy, we cannot be sure that we found all the relevant articles. Since we focused narrowly on keywords, and these had to be part of an article's title, we could have excluded relevant articles that used different terminology in their titles. Although searching the reference lists of identified articles did result in several additional articles, some relevant articles might still have been missed. Another limitation is the exclusion of publications in languages other than English. Further, the selection and categorization of specific findings, and

Table 7 Findings sorted by subject

\begin{tabular}{lcc}
\hline Subject & $\begin{array}{c}\text { Related } \\
\text { findings }\end{array}$ & $\begin{array}{c}\text { Nr. of } \\
\text { articles }\end{array}$ \\
\hline Leadership and involvement in the process & $\mathrm{C} 1, \mathrm{C} 2, \mathrm{C} 5, \mathrm{C} 8$ & 10 \\
Vendor & $\mathrm{A} 2, \mathrm{~B} 5$ & 3 \\
Implementation strategy & $\mathrm{C} 4, \mathrm{C} 5$, & 10 \\
Role of clinical staff (in particular & $\mathrm{C} 6, \mathrm{C} 7$, & 8 \\
the physicians) & $\mathrm{A} 3, \mathrm{C} 3$ & 6 \\
Users' skills/experience & $\mathrm{B} 2, \mathrm{~B} 3$ & 8 \\
EHR system & $\mathrm{A} 6, \mathrm{~B} 4$, & 7 \\
Patient issues & $\mathrm{A} 1$ & 4 \\
Hospital demographics & $\mathrm{A} 4$ & 4 \\
Organizational culture & $\mathrm{A} 5$ & 2 \\
Organizational structure & $\mathrm{B} 1$ & 6 \\
Fit between work processes and EHR system &
\end{tabular}


the subsequent extraction of general findings, is subjective and depends on the interpretations of the authors, and other researchers might have made different choices. A final limitation is inherent to literature reviews in that the authors of the studies included may have had different motives and aims, and used different methods and interpretative means, in drawing their conclusions.

\section{Conclusions}

The existing literature fails to provide evidence of there being a comprehensive approach to implementing EHR systems in hospitals that integrates relevant aspects into an 'EHR change approach'. The literature is diffuse, and articles seldom build on earlier ones to increase the theoretical knowledge on EHR implementation, notable exceptions being Aarts et al. [21], Aarts and Berg [22], Cresswell et al. [26], and Takian et al. [37]. The earlier discussion on the various results summarizes the existing knowledge and reveals gaps in the knowledge associated with EHR implementation. The number of EHR implementations in hospitals is growing, as well as the body of literature on this subject. This systematic review of the literature has produced 19 general findings on EHR implementation, which were each placed in one of three categories. A number of these general findings are in line with the wider literature on change management, and others relate to the specific nature of EHR implementation in hospitals.

The findings presented in this article can be viewed as an overview of important subjects that should be addressed in implementing an EHR system. It is clear that EHR systems have particular complexities and should be implemented with great care, and with attention given to context, content, and process issues and to interactions between these issues. As such, we have achieved our research goal by creating a systematic review of the literature on EHR implementation. This paper's academic contribution is in providing an overview of the existing literature with regard to important factors in EHR implementation in hospitals. Academics interested in this specific field can now more easily access knowledge on EHR implementation in hospitals and can use this article as a starting point and build on the existing knowledge. The managerial contribution lies in the general findings that can be applied as guidelines when implementing EHR in hospitals. We have not set out to provide a single blueprint for implementing an EHR system, but rather to provide guidelines and to highlight points that deserve attention. Recognizing and addressing these aspects can increase the likelihood of getting an EHR system successfully implemented.

\section{Appendix}

Appendix A - List of databases

This appendix provides an overview of all databases included in the used search engines. The databases in italic were excluded for the research as these databases focus on fields not relevant for the subject of EHR implementations.

\section{Web of Knowledge}

- 1) Web of Science

- 2) Biological Abstracts

- 3) Inspec

- 4) MEDLINE

- 5) Journal Citation Reports

\section{EBSCO}

- 1) Academic Search Premier

- 2) AMED - The Allied and Complementary Medicine Database

- 3) America: History \& Life

- 4) American Bibliography of Slavic and East European Studies

- 5) Arctic E Antarctic Regions

- 6) Art Full Text (H.W. Wilson)

- 7) Art Index Retrospective (H.W. Wilson)

- 8) ATLA Religion Database with ATLASerials

- 9) Business Source Premier

- 10) CINAHL

- 11) Communication E Mass Media Complete

- 12) eBook Collection (EBSCOhost)

- 13) EconLit

- 14) ERIC

- 15) Funk E Wagnalls New World Encyclopedia

- 16) GreenFILE

- 17) Historical Abstracts

- 18) L'Annéephilologique

- 19) Library, Information Science \& Technology Abstracts

- 20) MAS Ultra - School Edition

- 21) MEDLINE

- 22) Military E Government Collection

- 23) MLA Directory of Periodicals

- 24) MLA International Bibliography

- 25) New Testament Abstracts

- 26) Old Testament Abstracts

- 27) Philosopher's Index

- 28) Primary Search

- 29) PsycARTICLES

- 30) PsycBOOKS

- 31) PsycCRITIQUES

- 32) Psychology and Behavioral Sciences Collection

- 33) PsycINFO

- 34) Regional Business News

- 35) Research Starters - Business

- 36) RILM Abstracts of Music Literature

- 37) SocINDEX 


\section{The Cochrane Library}

- 1) Cochrane Database of Systematic Reviews

- 2) Cochrane Central Register of Controlled Trials

- 3) Cochrane Methodology Register

- 4) Database of Abstracts of Reviews of Effects

- 5) Health Technology Assessment Database

- 6) NHS Economic Evaluation Database

- 7) About The Cochrane Collaboration

\section{Appendix B - Quality assessment}

The quality of the articles was assessed with the Standard Quality Assessment Criteria for Evaluating Primary Research Papers [18]. Assessment was done by questioning whether particular criteria had been addressed, resulting in a rating of 2 (completely addressed), 1 (partly addressed), or 0 (not addressed) points. Table 8 provides the overview of the scores of the articles, (per question) for qualitative studies; Table 9 for quantitative studies; and Table 10 for mixed methods studies. Articles were included if they scored $50 \%$ or higher of the total amount of points possible. Based on this assessment, two articles were excluded from the search.

\section{Appendix C - All findings}

Table 11 displays all findings from the selected articles. The category number is related to the general finding as discussed in the Results section.

Table 8 Quality assessment results of qualitative studies

\begin{tabular}{|c|c|c|c|c|c|c|c|c|c|c|c|c|c|c|}
\hline Criteria qualitative studies & {$[21]$} & {$[22]$} & [24] & {$[25]$} & [26] & [28] & [31] & [32] & [33] & [34] & {$[35]$} & [36] & [37] & {$[40]$} \\
\hline $\begin{array}{l}\text { Question/objective sufficiently } \\
\text { described? }\end{array}$ & 2 & 2 & 2 & 2 & 2 & 2 & 2 & 2 & 1 & 2 & 1 & 2 & 1 & 2 \\
\hline $\begin{array}{l}\text { Study design evident and } \\
\text { appropriate? }\end{array}$ & 2 & 2 & 2 & 2 & 2 & 2 & 2 & 2 & 2 & 2 & 2 & 2 & 2 & 2 \\
\hline Context for the study clear? & 2 & 2 & 2 & 2 & 2 & 2 & 1 & 2 & 1 & 2 & 1 & 2 & 2 & 1 \\
\hline $\begin{array}{l}\text { Connection to a theoretical } \\
\text { framework/wider body of } \\
\text { knowledge? }\end{array}$ & 2 & 1 & 0 & 2 & 1 & 0 & 2 & 2 & 0 & 2 & 1 & 0 & 2 & 1 \\
\hline $\begin{array}{l}\text { Sampling strategy described, } \\
\text { relevant and justified? }\end{array}$ & 0 & 0 & 2 & 2 & 2 & 2 & 1 & 0 & 1 & 2 & 1 & 2 & 2 & 2 \\
\hline $\begin{array}{l}\text { Data collection methods clearly } \\
\text { described and systematic? }\end{array}$ & 1 & 1 & 2 & 2 & 2 & 2 & 1 & 2 & 2 & 1 & 1 & 2 & 1 & 2 \\
\hline $\begin{array}{l}\text { Data analysis clearly described } \\
\text { and systematic? }\end{array}$ & 0 & 0 & 1 & 1 & 1 & 2 & 0 & 1 & 1 & 2 & 1 & 2 & 1 & 2 \\
\hline $\begin{array}{l}\text { Use of verification procedure (s) } \\
\text { to establish credibility? }\end{array}$ & 0 & 2 & 2 & 0 & 1 & 1 & 0 & 0 & 0 & 0 & 0 & 1 & 2 & 0 \\
\hline $\begin{array}{l}\text { Conclusions supported by the } \\
\text { results? }\end{array}$ & 1 & 2 & 2 & 2 & 2 & 0 & 1 & 2 & 2 & 2 & 2 & 2 & 1 & 2 \\
\hline Reflexivity of the account? & 0 & 0 & 0 & 0 & 0 & 0 & 0 & 0 & 1 & 0 & 0 & 2 & 2 & 2 \\
\hline $\begin{array}{l}\text { Total score/possible maximum } \\
\text { score }\end{array}$ & $10 / 20$ & $12 / 20$ & $15 / 20$ & $15 / 20$ & $15 / 20$ & $13 / 20$ & $10 / 20$ & $13 / 20$ & $11 / 20$ & $15 / 20$ & $10 / 20$ & $17 / 20$ & $16 / 20$ & $16 / 20$ \\
\hline
\end{tabular}


Table 9 Quality assessment results of quantitative studies

\begin{tabular}{|c|c|c|c|c|c|c|c|}
\hline Criteria quantitative studies & [27] & [29] & [30] & [44] & [38] & [39] & [19] \\
\hline Question/objective sufficiently described? & 2 & 2 & 2 & 1 & 2 & 2 & 2 \\
\hline Study design evident and appropriate? & 2 & 2 & 2 & 1 & 2 & 2 & 2 \\
\hline $\begin{array}{l}\text { Method of subject/comparison group selection or source of information/input } \\
\text { variables described and appropriate? }\end{array}$ & 1 & 2 & 1 & 1 & 2 & 1 & 2 \\
\hline Subject (and comparison group, if applicable) characteristics sufficiently described? & 2 & 2 & 2 & 1 & 2 & 2 & 1 \\
\hline If interventional and random allocation was possible, was it described? & N/A & N/A & N/A & N/A & N/A & N/A & N/A \\
\hline If interventional and blinding of investigators was possible, was it reported? & N/A & N/A & N/A & N/A & N/A & N/A & N/A \\
\hline If interventional and blinding of subjects was possible, was it reported? & N/A & N/A & N/A & N/A & N/A & N/A & N/A \\
\hline $\begin{array}{l}\text { Outcome and (if applicable) exposure measure (s) well defined and robust to } \\
\text { measurement/misclassification bias? Means of assessment reported? }\end{array}$ & 0 & 2 & 1 & 0 & 2 & 2 & 2 \\
\hline Sample size appropriate? & 2 & 2 & 2 & 2 & 2 & 2 & 2 \\
\hline Analytic methods described/justified and appropriate? & 1 & 1 & 2 & 0 & 0 & 1 & 2 \\
\hline Some estimate of variance is reported for the main results? & 1 & 0 & 2 & 0 & 1 & 1 & N/A \\
\hline Controlled for confounding? & 2 & 1 & 2 & 0 & 1 & 1 & N/A \\
\hline Results reported in sufficient detail? & 2 & 2 & 2 & 1 & 2 & 2 & 2 \\
\hline Conclusions supported by the results? & 1 & 2 & 2 & 2 & 2 & 2 & 2 \\
\hline Total score/possible maximum score & $16 / 22$ & $19 / 22$ & $20 / 22$ & $9 / 22$ & $18 / 22$ & $18 / 22$ & $17 / 18$ \\
\hline
\end{tabular}

Table 10 Quality assessment results of mixed methods studies

\begin{tabular}{|c|c|c|}
\hline Qualitative criteria mixed methods studies & [23] & [43] \\
\hline Question/objective sufficiently described? & 1 & 2 \\
\hline Study design evident and appropriate? & 2 & 2 \\
\hline Context for the study clear? & 2 & 1 \\
\hline Connection to a theoretical framework/wider body of knowledge? & 0 & 1 \\
\hline Sampling strategy described, relevant and justified? & 1 & 0 \\
\hline Data collection methods clearly described and systematic? & 1 & 1 \\
\hline Data analysis clearly described and systematic? & 1 & 0 \\
\hline Use of verification procedure (s) to establish credibility? & 0 & 0 \\
\hline Conclusions supported by the results? & 1 & 1 \\
\hline Reflexivity of the account? & 0 & 0 \\
\hline \multicolumn{3}{|l|}{ Quantitative criteria mixed methods studies } \\
\hline Question/objective sufficiently described? & 1 & 2 \\
\hline Study design evident and appropriate? & 2 & 2 \\
\hline Method of subject/comparison group selection or source of information/input variables described and appropriate? & 2 & 1 \\
\hline Subject (and comparison group, if applicable) characteristics sufficiently described? & 1 & 0 \\
\hline If interventional and random allocation was possible, was it described? & N/A & N/A \\
\hline If interventional and blinding of investigators was possible, was it reported? & $\mathrm{N} / \mathrm{A}$ & N/A \\
\hline If interventional and blinding of subjects was possible, was it reported? & N/A & N/A \\
\hline $\begin{array}{l}\text { Outcome and (if applicable) exposure measure (s) well defined and robust to measurement/misclassification bias? } \\
\text { Means of assessment reported? }\end{array}$ & 2 & 0 \\
\hline Sample size appropriate? & 2 & N/A \\
\hline Analytic methods described/justified and appropriate? & 2 & 0 \\
\hline Some estimate of variance is reported for the main results? & 1 & 0 \\
\hline Controlled for confounding? & N/A & N/A \\
\hline Results reported in sufficient detail? & 2 & 0 \\
\hline Conclusions supported by the results? & 2 & 1 \\
\hline Total score/possible maximum score & $26 / 40$ & $14 / 38$ \\
\hline
\end{tabular}


Table 11 Overview of all findings

\section{Author}

Ash et al. [23]

Ash et al. [24]

Ash et al. [24]

Boyer et al. [25]

Boyer et al. [25]

Ford et al. [27]

Ford et al. [27]

Gastaldi et al. [28]

Gastaldi et al. [28]

Houser \& Johnson [29]

Houser \& Johnson [29]

Houser \& Johnson [29]

Jaana et al. [30]

Jaana et al. [30]

Ovretveit et al. [32]

Ovretveit et al. [32]

Ovretveit et al. [32]

Poon et al. [33]

Poon et al. [33]

Poon et al. [33]

Rivard et al. [34]

Scott et al. [35]

Takian et al. [37]

Ward et al. [38]

Ward et al. [38]

Ward et al. [39]

Weir et al. [19]

Weir et al. [19]

Weir et al. [19]

\section{Findings}

Category

Trust between administrators and physicians seems to be a necessary ingredient tot successful implementation.

Organizational issue fostering implementation: a strong culture

Organizational issue fostering implementation: a history of collaboration and teamwork

A favorable strategic factor is creating a favorable organizational culture.

The establishment of a multidisciplinary team to deal with her related issues prevents conflict and stimulates collaboration.

For-profit hospitals are half as likely to have fully implemented an EHR as their nonprofit counterparts.

System-affiliated hospitals were 31 percent more likely than were unaffiliated facilities to have successfully implemented an EHR.

Willingness to avoid pure cost-oriented vendors.

Diffused pressures to realize the EMR as soon as possible, because physicians' data sharing is needed.

Rural hospitals are less likely to have completed implementation of an EHR system compared to urban and suburban hospitals.

Government-owned or not-for-profit hospitals more often implemented a complete EHR system compared to for-profit hospitals.

A perceived barrier of implementing an EHR system is the lack of knowledge of EHR systems.

Critical Access Hospitals (CAH) in lowa have significantly lower EMR levels compared to non-CAHs.

A higher number of staffed beds and available slack resources is positively associated with higher clinical IS scores and EMR levels.

A facilitating factor in implementing an EMR system is the local hospital control of selection of the system.

A facilitating factor in implementing an EMR system is previous computer or EMR experience.

A facilitating factor in implementing an EMR system is the academic medical centre being more change ready.

A barrier to implementing CPOE is product and vendor immaturity.

Product and vendor immaturity can be overcome by selecting a vendor who is committed to the CPOE market.

Product and vendor immaturity can be overcome by ensuring a long-term trusting relationship of the vendor with the hospital.

The difficulty of a CIS implementation is explained by quality of care.

The organizational culture of cooperative values minimized resistance to change early on

In order to successfully implement an EHR stakeholders, and their computer literacy and ability to access the technology, need to be identified prior to planning to procure and implement EHR software.

Nurses who had previous experience with EHRs at other hospitals expressed more positive views towards an EHR.

Nurses with more years of health care experience had less favorable perceptions towards an EHR compared to nurses with less years of experience.

The staff perceived the EHR/CPOE implementation not to have disrupted the existing care processes.

A barrier to successful implementation of a CPOE is an uncooperative or computer phobic attitude of physicians.

A barrier to successful implementation of a CPOE is bureaucracy preventing change and interdepartmental conflict.

A barrier to successful implementation of a CPOE is health care providers that don't know how to type.

\section{A5} (1) A 1 . 
Table 11 Overview of all findings (Continued)

Weir et al. [19]

Aarts et al. [21]

Aarts et al. [21]

Ash et al. [24]

Ash et al. [24]

Ash et al. [24]

Ash et al. [24]

Ash et al. [24]

Boyer et al. [25]

Boyer et al. [25]

Cresswell et al. [26]

Gastaldi et al. [28]

Houser \& Johnson [29]

Houser \& Johnson [29]

Katsma et al. [31]

Ovretveit et al. [32]

Ovretveit et al. [32]

Ovretveit et al. [32]

Poon et al. [33]

Scott et al. [35]

Takian et al. [37]

Takian et al. [37]

Takian et al. [37]

Weir et al. [19]

Weir et al. [19]

Weir et al. [19]

Weir et al. [19]

Weir et al. [19]

Weir et al. [19]

Weir et al. [19]

Yoon-Flannery et al. [40]
Support staff identify the barrier bureaucracy significantly more often than physicians.

Implementation of a CPOE is both a social process and contains technical issues, which increases complexity.

Creating fit between technology and work practices is a key factor for successful implementation of information systems.

Technical/implementation issue fostering implementation: speed of the system

Technical/implementation issue fostering implementation: the ability to group orders into order sets

Technical/implementation issue fostering implementation: the possibility to make clinical pathways available to health care teams,

Technical/implementation issue fostering implementation: the possibility to enter orders from remote locations.

Organization of information issue fostering implementation: the information must be organized in a manner designed to mimic the way in which people use the information, which is generally not in a structured, hierarchical manner.

The technical aspects of an EMR have an important place but do not necessarily guarantee a successful implementation of EMR.

A barrier in implementing an EMR is less confidentiality in information sharing between patient and professional.

A barrier in implementing an EHR is limited ability to customize the software.

Being able to deal with technical problems related to the customization of the system.

A perceived barrier of implementing an EHR system is the lack of structured technology.

Perceived barriers of implementing an EHR system are privacy and confidentiality issues.

Compatibility of the EPR with working processes can also be reached by changing the work processes.

A factor in implementing an EMR system is the ease of navigation, efficiency in use and accessibility of the system.

A factor in implementing an EMR system is the absence of failures

A factor in implementing an EMR system is physicians' acceptance and implementer's responsiveness to concerns.

Product and vendor immaturity can be overcome by having the vendor willing to adapt its product to hospital workflow issues.

Software design and development problems increased local resistance.

EHR needs to be seen as a sociotechnical entity by stakeholders, ensuring a user-centered design of EHR.

Because of the huge cultural shift an EHR brings to heavily text-based notes, healthcare practitioners must be educated and protected with regards to transparency and observing confidentiality of patient notes.

The safety of information access to EHR systems needs to be ensured prior to and during the implementation.

A facilitating factor associated with implementation of a CPOE is sufficient functionality of the system.

A facilitating factor associated with I implementation of a CPOE is the ability to customize software to meet physician needs.

A facilitating factor associated with implementation of a CPOE is adequate hardware, terminals, etc.

A barrier to implementation of a CPOE is insufficient functionality of the software.

A barrier to implementation of a CPOE is having an insufficient number of terminals, a too slow system, and non-portable screens.

A barrier to implementation of a CPOE is a user-unfriendly system.

A barrier to implementation of a CPOE is a too labor intensive program.

EHR implementation best practice contains sufficient hardware, technical equipment, support and training. 
Table 11 Overview of all findings (Continued)

Yoon-Flannery et al. [40]

Aarts et al. [21]

Ash et al. [24]

Boyer et al. [25]

Boyer et al. [25]

Boyer et al. [25]

Cresswell et al. [26]

Cresswell et al. [26]

Cresswell et al. [26]

Cresswell et al. [26]

Gastaldi et al. [28]

Gastaldi et al. [28]

Gastaldi et al. [28]

Gastaldi et al. [28]

Houser \& Johnson [29]

Katsma et al. [31]

Ovretveit et al. [32]

Ovretveit et al. [32]

Ovretveit et al. [32]

Ovretveit et al. [32]

Ovretveit et al. [32]

Ovretveit et al. [32]

Simon et al. [36]

Simon et al. [36]

Simon et al. [36]

Simon et al. [36]

Simon et al. [36]

Simon et al. [36]

Simon et al. [36]

Scott et al. [35]

Scott et al. [35]

Scott et al. [35]

Weir et al. [19]

Weir et al. [19]

Weir et al. [19]
EHR implementation best practice contains adequate safeguards for patient privacy.

B4

Emergent change is a key characteristic of implementing information systems in complex organizations.

Organizational issue fostering implementation: supportive leadership

C1

The strategy used for EMR implementation is particularly important

A favorable strategic factor is active involvement of the manager.

A favorable strategic factor is regularly assessing the views of professionals to identify problems and develop support for corrective action.

Allowing intensive user involvement in software design is favorable for embedding the system of time (particularly in smaller scale implementations).

Acceptance of initially parallel use of paper during the implementation.

Resistance of powerful users can lead to 'workarounds'

There is time and resources available to let the users familiarize with the system.

Engagement of the whole organization in the process is crucial (both the creation as well as the maintenance).

Management of the change is crucial, particularly its initial communication.

Initial technological resistance of the physicians is a problem.

Understanding of the physicians' necessities is important.

A perceived barrier of implementing an EHR system is the lack of employee training.

Development paradigm implementation approaches go hand in hand with high levels of implementation.

A helping factor in implementing an EMR system is employee involvement in many different ways.

A helping factor in implementing an EMR system is leadership and support by a competent on site information technology department.

A helping factor in implementing an EMR system is decisive and full leadership backing.

A factor in implementing an EMR system is providing education at the right times, amount and quality.

A factor in implementing an EMR system is strong management support.

The entity that manages the implementation of CPOE needs to have representation from among the staff members (front line representation).

Training end-users is important; providing real-time support is even more important.

CPOE implementation requires a great deal of planning and preparation in advance.

Multi-disciplinary representation of front line users and collaboration is important for the implementation of CPOE.

Awareness of attitudes of anxiety and fear is important in the planning of the implementation of CPOE.

The identification and support of a champion among each user group.

The ample presence of live, in-person support (super-users) is helpful in facilitating the CPOE implementation.

The initial selection of the CIS was perceived to be detached from the local environment resulting in conflicting priorities between the organization and individual physicians.

Participatory leadership was valued for selection decisions.

Hierarchical leadership was valued for implementation.

A facilitating factor associated with the implementation of a CPOE is knowledgeable, cheerful support from the Information Resource Management department.

A facilitating factor associated with the implementation of a CPOE is supportive administration and chiefs of staff.

A facilitating factor associated with the implementation of a CPOE is direct involvement of physicians. 
Table 11 Overview of all findings (Continued)

Weir et al. [19]

Weir et al. [19]

Weir et al. [19]

Weir et al. [19]

Weir et al. [19]

Weir et al. [19]

Weir et al. [19]

Weir et al. [19]

Weir et al. [19]

Weir et al. [19]

Weir et al. [19]

Weir et al. [19]

Weir et al. [19]

Weir et al. [19]

Weir et al. [19]

Yoon-Flannery et al. [40]

Yoon-Flannery et al. [40]

Yoon-Flannery et al. [40]

Aarts \& Berg [22]

Ash et al. [24]

Houser \& Johnson [29]

Ovretveit et al. [32]

Poon et al. [33]

Poon et al. [33]

Aarts et al. [21]

Ovretveit et al. [32]

Poon et al. [33]

Poon et al. [33]

Poon et al. [33]

Rivard et al. [34]
A facilitating factor associated with the implementation of a CPOE is a good working relationship with developers.

A facilitating factor associated with the implementation of a CPOE is an interdisciplinary, effective implementation group.

A facilitating factor associated with the implementation of a CPOE is a good implementation strategy.

A facilitating factor associated with the implementation of a CPOE is support by medical administration and other allied fields.

A facilitating factor associated with the implementation of a CPOE is mandatory implementation.

A facilitating factor associated with the implementation of a CPOE is good training and instruction.

A barrier to the implementation of a CPOE is inadequate training, insufficient material, and residents rotation.

A barrier to the implementation of a CPOE is the lack of effective, cheerful Information Resource Management support.

A barrier to the implementation of a CPOE is non-supportive section chiefs of staff.

Support staff identifies the facilitating factor organized, interdisciplinary implementation group significantly more often than physicians.

Physicians identify the facilitating factor support of chiefs of staff and medical administration significantly more often than support staff.

Physicians identify the facilitating factor mandatory implementation significantly more often than support staff.

A facilitating factor associated with successful implementation of a CPOE is having a sufficient number of people for implementation and user training.

A barrier to successful implementation of a CPOE is insufficient personnel to adequately implement the system and train people.

Support staff identifies the facilitating factor sufficient personnel for implementation significantly more often than physicians.

EHR implementation best practice contains effective, clear communication.

EHR implementation best practice contains careful planning for system migration.

EHR implementation best practice contains a sustainable business plan.

Accepting or rejecting an information system will depend on whether those involved in the medical work practices will accept a transformation of these practices.

Clinical/Professional issue fostering implementation: customization and the ability to adapt POE at the local level, creating acceptance among physicians.

A perceived barrier of implementing an EHR system is the lack of support from medical staff.

A facilitating factor in implementing an EMR system is having adequate people and financial resources.

A barrier to implementing CPOE is physician and organizational resistance.

Physician and organizational resistance can be overcome by addressing workflow concerns.

The implementation process of a CPOE is highly unpredictable, influenced by contingencies that were not expected nor planned for.

A factor in implementing an EMR system is having a physician champion.

Physician and organizational resistance can be overcome by strong leadership

Physician and organizational resistance can be overcome by identifying physician champions.

Physician and organizational resistance can be overcome by leveraging house staff or hospitalists.

The difficulty of a CIS implementation is explained by physicians' medical dominance. 
Table 11 Overview of all findings (Continued)

\begin{tabular}{ll}
\hline Rivard et al. [34] & The difficulty of a CIS implementation is explained by other health professionals' \\
& professional status and autonomy. \\
Takian et al. [37] & Contextualization and taking heterogeneity across mental health settings is crucial to \\
& implement EHR initiatives, it might help identify areas in need of additional support.
\end{tabular}

\section{Competing interests}

The authors declare that they have no competing interests.

\section{Authors' contributions}

$A B$ and JV established the research design and made significant contributions to the interpretation of the results. They supervised AV throughout the study, and participated in writing the final version of this paper. AV contributed substantially to the selection and analysis of included papers, and wrote a preliminary draft of this article. All authors have read and approved the final manuscript.

\section{Acknowledgement}

We acknowledge the Master degree program Change Management at the University of Groningen for supporting this study. We also thank the referees for their valuable comments.

\section{Author details}

${ }^{1}$ Faculty of Economics and Business, University of Groningen, Groningen, The Netherlands. ${ }^{2}$ Deloitte Consulting, Amsterdam, The Netherlands.

Received: 23 September 2013 Accepted: 11 August 2014

Published: 4 September 2014

\section{References}

1. Abramson EL, McGinnis S, Edwards A, Maniccia DM, Moore J, Kaushal R: Electronic health record adoption and health information exchange among hospitals in New York State. J Eval Clin Pract 2011, 18:1156-1162.

2. Robertson A, Cresswell K, Takian A, Petrakaki D, Crowe S, Cornford T, Sheikh A: Implementation and adoption of nationwide electronic health records in secondary care in England: qualitative analysis of interim results from a prospective national evaluation. Br Med J 2010, 341:C4564.

3. Rigsrevisionen: Extract from the report to the Public Accounts Committee on the implementation of electronic patient records at Danish hospitals; 2011. http://uk.rigsrevisionen.dk/media/1886186/4-2010.pdf, 2011.

4. Hartswood M, Procter R, Rouncefield M, Slack R: Making a Case in Medica Work: Implications for the Electronic Medical Record. Comput Supported Coop Work 2003, 12:241-266.

5. Grimson J, Grimson W, Hasselbring W: The SI Challenge in Health Care. Commun ACM 2000, 43(6):49-55.

6. Mantzana V, Themistocleous M, Irani Z, Morabito V: Identifying healthcare actors involved in theadoption of information systems. Eur J Inf Syst 2007, 16:91-102.

7. Boonstra A, Boddy D, Bell S: Stakeholder management in IOS projects: analysis of an attempt to implement an electronic patient file. Eur J Inf Syst 2008, 17(2):100-111.

8. Jha A, DesRoches CM, Campbell EG, Donelan K, Rao SR, Ferris TF, Shields A Rosenbaum S, Blumenthal D: Use of Electronic Health Records in US hospitals. N Engl J Med 2009, 360:1628-1638.

9. Heeks R: Health information systems: Failure, success and improvisation. Int J Med Inform 2006, 75:125-137.

10. Boonstra A, Govers MJ: Understanding ERP system implementation in a hospital by analysing stakeholders. N Technol Work Employ 2009, 24(2):177-193.

11. Keshavjee K, Bosomworth J, Copen J, Lai J, Kucukyazici B, Liani R, Holbrook AM: Best practices in EMR implementation: a systematic review. In Proceed of the 11th International Symposium on Health Information Mangement Research - iSHIMR. ; 2006:1-15.

12. McGinn CA, Grenier S, Duplantie J, Shaw N, Sicotte C, Mathieu L, Leduc Y, Legare F, Gagnon MP: Comparison of use groups perspectives of barriers and facilitator to implementing EHR - a systematic review. BMC Med 2011, 9:46.
13. Pettigrew AM: Context and action in the transformation of the firm. J Manag Stud 1987, 24(6):649-670.

14. Hartley J: Case Study Research. Chapter 26. In Essential Guide to Qualitative Methods in Organizational Research. Edited by Cassel C, Symon G. London: Sage; 2004.

15. Hage E, Roo JP, Offenbeek MAG, Boonstra A: Implementation factors and their effect on e-health service adoption in rural communities: a systematic literature review. BMC Health Serv Res 2013, 13(19):1-16.

16. ISO: Health informatics: Electronic health record - Definition, scope and context. Draft Tech Report 2004:03-16. ISO/DTR 20514. available at https://www.iso.org/obp/ui/\#iso:std:iso:tr:20514:ed-1:v1:en.

17. Häyrinen K, Saranto K, Nykänen P: Definition, structure, content, use and impacts of electronic health records: A review of the research literature Int J Med Inform 2008, 77:291-304.

18. Kaushal R, Shojania KG, Bates DW: Effects of computerized physician order entry and clinical decision support systems on medication safety: a systematic review. Arch Intern Med 2003, 163(12):1409-1416.

19. Weir C, Lincoln M, Roscoe D, Turner C, Moreshead G: Dimensions associated with successful implementation of a hospital based integrated order entry system. Proc Annu Symp Comput Appl [Sic] in Med Care Symp Comput Appl Med Care 1994, 653:7.

20. Kmet LM, Lee RC, Cook LS: Standard quality assessment criteria for evaluating primary research papers from a variety of fields. Alberta Heritage Foundation for Medical Research; 2004. http://www.ihe.ca/documents/HTA-FR13.pdf.

21. Aarts J, Doorewaard H, Berg M: Understanding implementation: The case of a computerized physician order entry system in a large dutch university medical center. J Am Med Inform Assoc 2004, 11(3):207-216.

22. Aarts J, Berg M: Same systems, different outcomes - Comparing the implementation of computerized physician order entry in two Dutch hospitals. Methods Inf Med 2006, 45(1):53-61.

23. Ash J, Gorman P, Lavelle M, Lyman J, Fournier L: Investigating physician order entry in the field: lessons learned in a multi-center study. Stud Health Technol Inform 2001, 84(2):1107-1111.

24. Ash JS, Gorman PN, Lavelle M, Payne TH, Massaro TA, Frantz GL, Lyman JA: A cross-site qualitative study of physician order entry. J Am Med Inform Assoc 2003, 10(2):188-200.

25. Boyer L, Samuelian J, Fieschi M, Lancon C: Implementing electronic medical records in a psychiatric hospital: A qualitative study. Int J Psychiatry Clin Pract 2010, 14(3):223-227.

26. Cresswell KM, Worth A, Sheikh A: Integration of a nationally procured electronic health record system into user work practices. BMC Med Inform Decis Mak 2012, 12:15.

27. Ford EW, Menachemi N, Huerta TR, Yu F: Hospital IT Adoption Strategies Associated with Implementation Success: Implications for Achieving Meaningful Use. J Healthc Manag 2010, 55(3):175-188.

28. Gastaldi L, Lettieri E, Corso M, Masella C: Performance improvement in hospitals: leveraging on knowledge assets dynamics through the introduction of an electronic medical record. Meas Bus Excell 2012, 16(4):14-30.

29. Houser SH, Johnson LA: Perceptions regarding electronic health record implementation among health information management professionals in Alabama: a statewide survey and analysis. Perspect Health Inf Manage/AHIMA, Am Health Inf Manage Assoc 2008, 5:6-6.

30. Jaana M, Ward MM, Bahensky JA: EMRs and Clinical IS Implementation in Hospitals: A Statewide Survey. J Rural Health 2012, 28:34-43.

31. Katsma CP, Spil TAM, Ligt E, Wassenaar A: Implementation and use of an electronic health record: measuring relevance and participation in four hospitals. Int J Healthc Technol Manag 2007, 8(6):625-643.

32. Ovretveit J, Scott T, Rundall TG, Shortell SM, Brommels M: Improving quality through effective implementation of information technology in healthcare. Int J Qual Health Care 2007, 19(5):259-266.

33. Poon EG, Blumenthal D, Jaggi T, Honour MM, Bates DW, Kaushal R: Overcoming barriers to adopting and implementing computerized 
physician order entry systems in US hospitals. Health Aff 2004, 23(4):184-190.

34. Rivard S, Lapointe L, Kappos A: An Organizational Culture-Based Theory of Clinical Information Systems Implementation in Hospitals. J Assoc Inf Syst 2011, 12(2):123-162.

35. Scott JT, Rundall TG, Vogt TM, Hsu J: Kaiser Permanente's experience of implementing an electronic medical record: a qualitative study. $\mathrm{Br}$ Med J 2005, 331(7528):1313-1316.

36. Simon SR, Keohane CA, Amato M, Coffey M, Cadet M, Zimlichman E: Lessons learned from implementation of computerized provider order entry in 5 community hospitals: a qualitative study. BMC Med Inform Decis Mak 2013, 13:67.

37. Takian A, Sheikh A, Barber N: We are bitter, but we are better off: case study of the implementation of an electronic health record system into a mental health hospital in England. BMC Health Serv Res 2012, 12:484.

38. Ward MM, Vartak S, Schwichtenberg T, Wakefield DS: Nurses' Perceptions of How Clinical Information System Implementation Affects Workflow and Patient Care. Cin-Comput Inform Nurs 2011, 29(9):502-511.

39. Ward MM, Vartak S, Loes JL, O'Brien J, Mills TR, Halbesleben JRB, Wakefield DS: CAH Staff Perceptions of a Clinical Information System Implementation. Am J Manage Care 2012, 18(5):244-252.

40. Yoon-Flannery K, Zandieh SO, Kuperman GJ, Langsam DJ, Hyman D, Kaushal R: A qualitative analysis of an electronic health record (EHR) implementation in an academic ambulatory setting. Inform Prim Care 2008, 16(4):277-284.

41. Van Aken J, Berends $\mathrm{H}$, Van der Bij H: Problem solving in organizations. New York, USA: Cambridge University Press; 2012.

42. Botha ME: Theory development in perspective: the role of conceptual frameworks and models in theory development. J Adv Nurs 1989, 14(1):49-55.

43. Spetz J, Keane D: Information Technology Implementation in a Rural Hospital: A Cautionary Tale. J Healthc Manag 2009, 54(5):337-347.

44. Massaro TA: Introducing Physician Order Entry at a Major Academic Medical-Center. Impact Organ Culture Behav Acad Med 1993, 68(1):20-25.

45. Lundberg S, Bergman M: Tender evaluation and supplier selection methods in public procurement. J Purch Supply Manage 2013, 19(2):73-83.

46. Kanter RM, Stein BA, Jick TD: The Challenge of Organizational Change. New York, USA: Free Press; 1992

doi:10.1186/1472-6963-14-370

Cite this article as: Boonstra et al:: Implementing electronic health records in hospitals: a systematic literature review. BMC Health Services Research 2014 14:370.

\section{Submit your next manuscript to BioMed Central and take full advantage of:}

- Convenient online submission

- Thorough peer review

- No space constraints or color figure charges

- Immediate publication on acceptance

- Inclusion in PubMed, CAS, Scopus and Google Scholar

- Research which is freely available for redistribution 